\title{
The Role of Molecule Clustering by Hydrogen Bond in Hydrous Ethanol on Laminar Burning Velocity
}

\author{
I Made Suarta, ${ }^{1,2}$ I. N. G. Wardana, ${ }^{2}$ Nurkholis Hamidi, ${ }^{2}$ and Widya Wijayanti ${ }^{2}$ \\ ${ }^{1}$ Mechanical Engineering Department, Bali State Polytechnic, Badung, Bali 80361, Indonesia \\ ${ }^{2}$ Department of Mechanical Engineering, University of Brawijaya, Malang, East Java, Indonesia \\ Correspondence should be addressed to I Made Suarta; suarta_bedil@yahoo.com
}

Received 16 January 2016; Revised 28 April 2016; Accepted 17 May 2016

Academic Editor: Satyanarayanan R. Chakravarthy

Copyright (C) 2016 I Made Suarta et al. This is an open access article distributed under the Creative Commons Attribution License, which permits unrestricted use, distribution, and reproduction in any medium, provided the original work is properly cited.

\begin{abstract}
The role of hydrogen bond molecule clustering in laminar burning velocities was observed. The water in hydrous ethanol can change the interaction between water-ethanol molecules. A certain amount of water can become oxygenated which increases the burning velocity. The hydrogen bond interaction pattern of ethanol and water molecules was modeled. Based on the molecular model, azeotropic behavior emerges from ethanol-water hydrogen bond, which is at a $95.1 \% \mathrm{v}$ composition. The interaction with water molecule causes the ethanol molecule to be clustered with centered oxygenated compound. So, it supplies extra oxygen and provides intermolecular empty spaces that are easily infiltrated by the air. In the azeotropic composition, the molecular bond chain is the shortest, so hypothetically the burning velocity is anticipated to increase. The laminar burning velocity of ethanol fuel was tested in a cylindrical explosion bomb in lean, stoichiometric, and rich mixtures. The experimental result showed that the maximum burning velocity occurred at hydrous ethanol of $95.5 \% \mathrm{v}$ composition. This discrepancy is the result of the addition of energy from $7.7 \%$ free ethanol molecules that are not clustered. At the rich mixture, the burning velocity of this composition is higher than that of anhydrous ethanol.
\end{abstract}

\section{Introduction}

The use of anhydrous ethanol as fuel needs extraordinarily high energy in the purification process [1-4]. Hydrous ethanol (also often referred to as azeotropic ethanol) is ethanol with little content of water that can be produced by simple distillation process without any further distillation $[2,5]$. Hydrous ethanol evaporates at the temperature of $78.1^{\circ} \mathrm{C}[4]$ compared to the pure ethanol which evaporates at the temperature of $78.8^{\circ} \mathrm{C}$ [6]. This suggests that distillation cannot produce ethanol with purity above azeotropic level.

One of the ways of reducing production cost of bioethanol is by using it with little water content. Today, normal composition of hydrous ethanol fuel (azeotropic) is about $93.2 \% \mathrm{v}$ (186 proof) to $96.5 \% \mathrm{v}$ (195 proof) $[2,4,6]$. Though hydrous ethanol has many advantages, its energy density is low. Its heating value is $24.99 \mathrm{MJ} / \mathrm{kg}[2,4]$ compared to anhydrous ethanol whose heating value is $26.8 \mathrm{MJ} / \mathrm{kg}[7,8]$ and to gasoline whose heating value is $44 \mathrm{MJ} / \mathrm{kg}[4,7]$.
The study using hydrous ethanol as a fuel of engine has been performed by many researchers $[1,2,4,5,7,9,10]$. They suggest that hydrous ethanol increases the balance between the energy needed during production and the power produced. Hydrous ethanol produces higher power, better emission quality, and shorter burning duration.

Bradley et al. [3] studied hydrous ethanol flame velocity at a $96.6 \% \mathrm{v}$ composition. The fuel is vaporized by atomization method. Their results show that at equivalence ratio of 1.1 flame velocity of anhydrous ethanol is $2.7 \mathrm{~m} / \mathrm{s}$ whereas that of hydrous ethanol is $2.6 \mathrm{~m} / \mathrm{s}$.

Breaux and Acharya [6] observed flammability limit of ethanol and water mixture (the lowest ER) in diffusion combustion with swirl stabilizer. They used hydrous ethanol with a $0-40 \%$ v water composition. They found that LBO (lean blow-out limit $=$ the lowest limit of equivalence ratio) increases proportionally to water content. However, the LBO decreases at azeotropic ethanol.

Research of hydrous ethanol was motivated by those who discovered previously that the burning characteristic of 


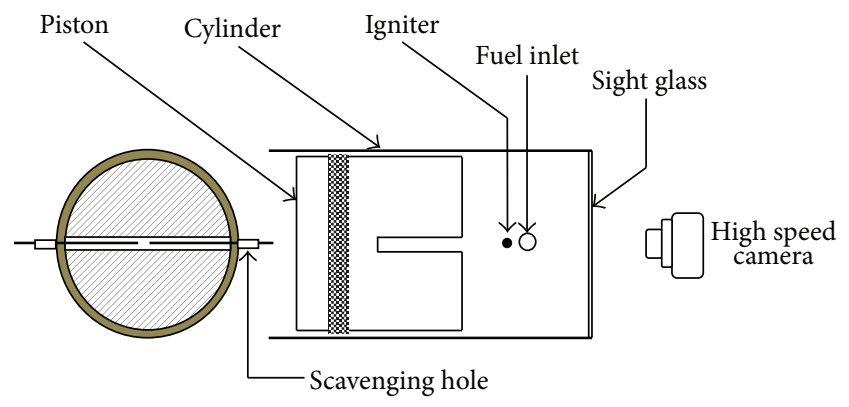

FIGURE 1: Experimental setup.

hydrous ethanol is better than of anhydrous ethanol especially at azeotropic composition [2]. However, until today, the scientific evidence has not been clearly revealed. Since ethanol contains little water, the hydrogen bonding is considered to play an important role.

This study reveals that the azeotropic ethanol molecule cluster is constructed by ethanol-water molecules based on hydrogen bond at a certain composition. This research also provides the laminar burning velocity of hydrous ethanol.

\section{Experiment Setup and Procedure}

Premixed combustion process of hydrous ethanol was observed in a cylindrical explosion combustion chamber with diameter of $135 \mathrm{~mm}$ and a length of $270 \mathrm{~mm}$ as shown in Figure 1. This model has been used by [3]. One end of the chamber was closed with transparent glass wall for capturing flame growth video with a high speed camera. The other end was a piston which could move freely during the development of the flame ball. The left side wall of the cylinder was fitted with positive $(+)$ terminal of an igniter and fuel inlet for insertion of reactants. The right side wall was mounted with negative (-) terminal of the igniter and scavenging manifold.

The fuel used in this experiment was ethanol with purity of $99.7 \% \mathrm{v}$ and hydrous ethanol was made in the analytical laboratory. The test was conducted at atmospheric pressure and ambient temperature at $305 \mathrm{~K}$. The fuel was mixed with air in the mixing chamber in certain equivalence ratio and was evaporated. The mixture was inserted into the combustion chamber through the fuel inlet. Before igniting, the high speed camera was turned on and set up at a speed of $420 \mathrm{fps}$.

Laminar burning velocity of hydrous ethanol was estimated from flame images influenced by the equivalence ratio $(\phi)$, fuel heating value, and adiabatic flame temperature.

Adiabatic flame temperature is affected by water content of the fuel as shown in Figure 2. It is shown that the increasing water content reduces the adiabatic flame temperature. Adiabatic flame temperature decreases proportionally to the increase in latent heat evaporation of water content [6]. Therefore, hydrous ethanol requires more heat to vaporize. The adiabatic flame temperature increases with the increasing equivalence ratio due to the feeding of more fuel in the combustion process. Adiabatic flame temperature is estimated using the formula in [11]. The results are consistent with the results obtained by [6] using NASA CEA code 12 .

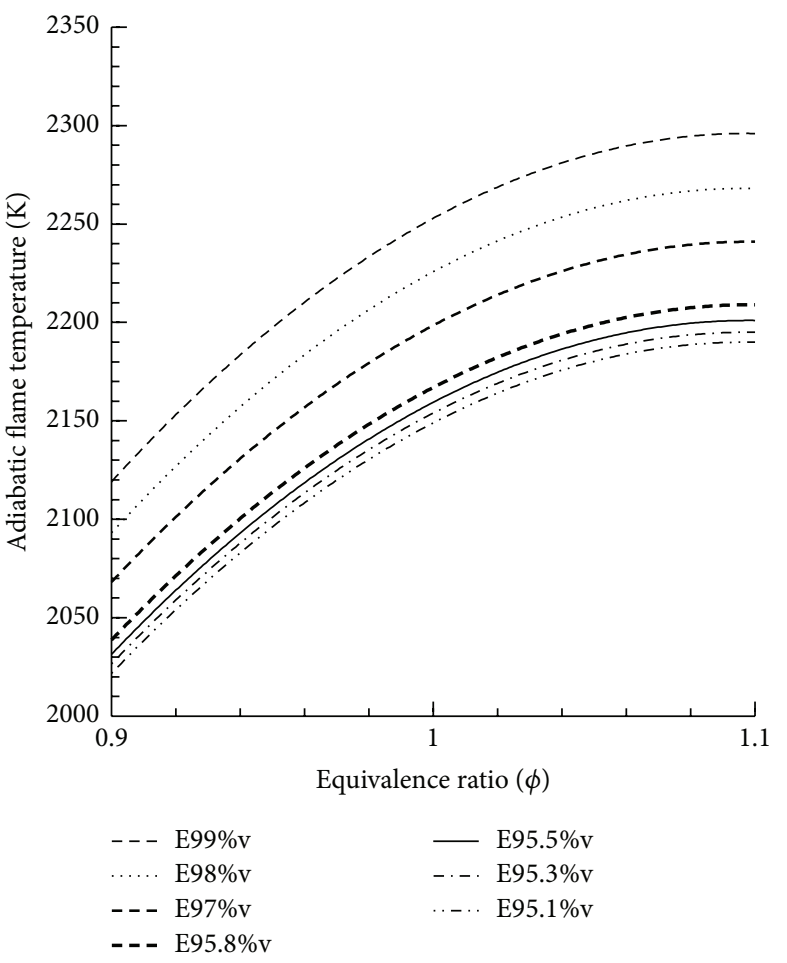

FIGURE 2: Adiabatic flame temperature of ethanol function of water content.

The low heating value (LHV) of hydrous ethanol was determined based on the water content in the ethanol. LHV of hydrous ethanol was obtained by multiplying the mass percentage of hydrous ethanol with LHV anhydrous ethanol. The calorific value of hydrous ethanol at each water content can be determined using LHV data of anhydrous ethanol of $26.8 \mathrm{MJ} / \mathrm{kg}[8,12,13]$.

\section{Flame Analysis}

The stretched flame speed, $S_{n}$, is estimated utilizing method in [12-15] as follows:

$$
S_{n}=\frac{d r}{d t}
$$

in which $r$ is the radius of the spherical flame front and $t$ is the time when $r$ is measured. The stretched rate $(\alpha)$ of spherical flame is obtained at any captured image on the surface of the flame [12] as follows:

$$
\alpha=\frac{d(\ln A)}{d t}=\frac{d A / A}{d t}=\frac{d A}{A \cdot d t} .
$$

In this equation, $A$ is the surface area of the flame. In the case of spherical propagating premixed flame, the flame stretched rate can be calculated as

$$
\alpha=\frac{d A}{A \cdot d t}=\left(\frac{2}{r}\right)\left(\frac{d r}{d t}\right)=\left(\frac{2}{r}\right) S_{n} .
$$




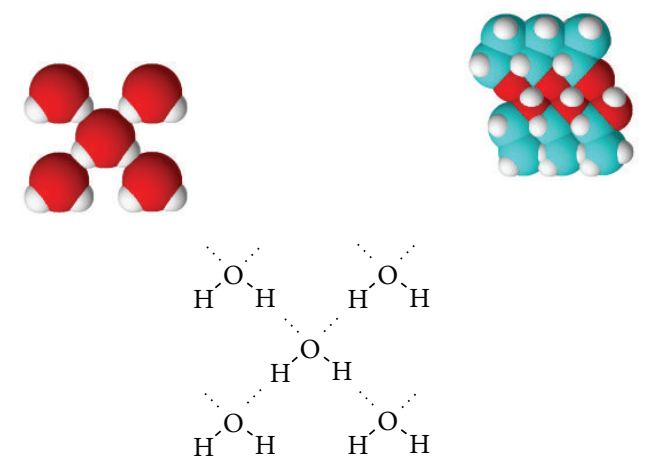

(a)

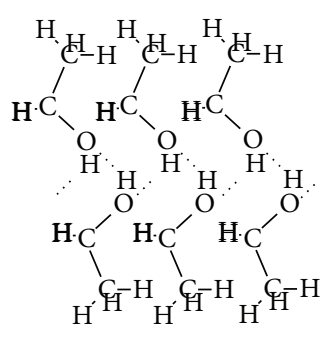

(b)

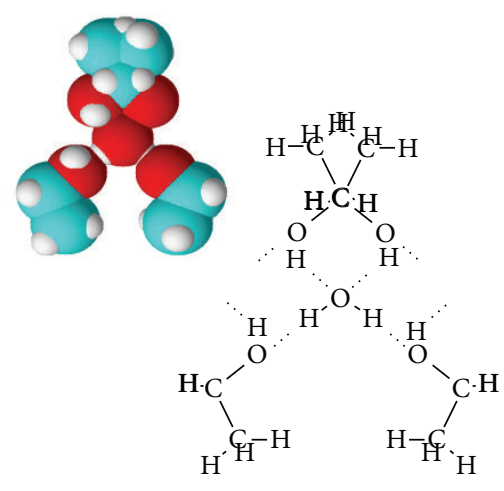

(c)

Figure 3: (a) Molecular structure of water. (b) Molecular structure of ethanol. (c) Molecular structure of ethanol-water.

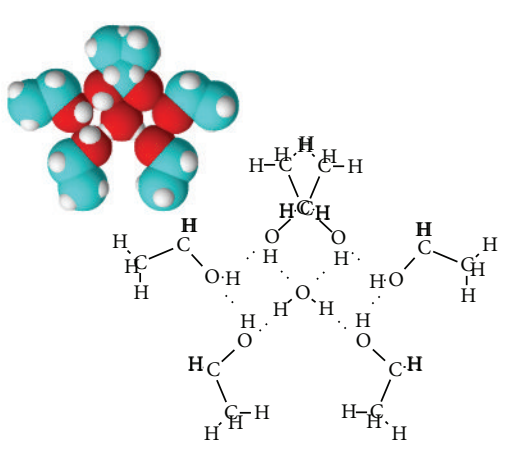

(a)

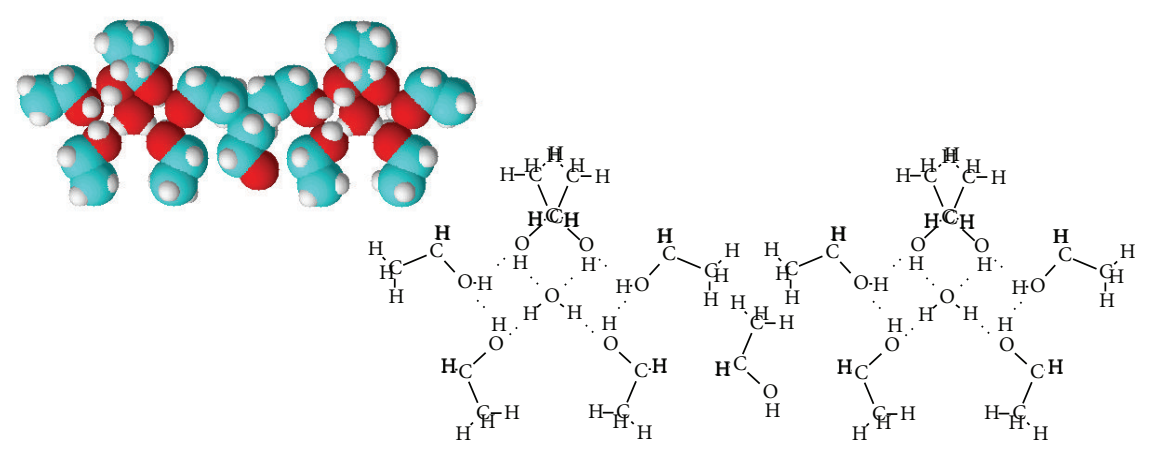

(b)

Figure 4: (a) Molecular structure of ethanol of $95.1 \%$ v. (b) Molecular structure of ethanol of $95.5 \%$ v.

A linear relationship between the unstretched flame speed $\left(S_{s}\right)$ and stretched flame speed has been reported in [13$16]$ as in

$$
S_{s}-S_{n}=L_{b} \cdot \alpha .
$$

It can be seen from (4) that $S_{s}$ is equal to $S_{n}$ at $\alpha=0$. Laminar burning velocity $\left(S_{L}\right)$ is derived from $S_{s}$ as

$$
S_{L}=\frac{\rho_{b}}{\rho_{u}} S_{s},
$$

in which $\rho_{b}$ and $\rho_{u}$ are the density of combustion gases and the density of the reactants, respectively.

\section{Results and Discussion}

4.1. Effect of Hydrogen Bond to Molecular Structure. The molecular structure of ethanol and water was described by using "ChemSketch" software [17]. However, the molecular structure of hydrous ethanol was built based on hydrogen bonds principle and solubility theory of polar molecule. Each water molecule binds four molecules of water (Figure 3(a)) [18]. Also, each ethanol molecule binds two other nearby molecules as in Figure 3(b) [19].

In case of less water soluble in ethanol, the water molecule is surrounded by ethanol molecules due to larger electronegativity difference. Polar heads facing inward attract each other while nonpolar tails facing outward avoid each other. Polar structure of ethanol-water has two hydrogen bonds, in which ethanol is a proton acceptor $\mathrm{RHO}-\mathrm{H}_{2} \mathrm{O}$ or proton donor $\mathrm{ROH}-\mathrm{OH}_{2}$ [19]. The description is illustrated in Figure 3(c).

Figure 3(c) shows that two left side molecules of ethanol bind other polar molecules, either ethanol or water molecules. Two right side molecules of ethanol do similarly. When two molecules of ethanol are added to the group to increase the heat value, the molecular structure forms a group with the shortest chain length as shown in Figure 4(a).

In the hydrous ethanol molecule group shown in Figure 4(a), there are one water molecule and six ethanol molecules. One water molecule has molecular mass $(M)=$ $18.015 \mathrm{~g} / \mathrm{mol}$ and density $(\rho)=1 \mathrm{~g} / \mathrm{cc}$, and then the volume is $18.015 \mathrm{cc}$. Six molecules of ethanol have molecular mass $(M)=46.068 \mathrm{~g} / \mathrm{mol}$ and $\rho=0.789 \mathrm{~g} / \mathrm{cc}$, with volume $=$ $350.327 \mathrm{cc}$. The volume fraction of these 6 ethanol molecules is $95.1 \% \mathrm{v}$.

Based on the molecule model, the ethanol of $95.1 \% \mathrm{v}$ has at least a group of molecules because the group is not able to bind other molecules and become very stable. Therefore, this molecular structure has the lowest evaporation temperature due to the shorter fuel molecules. Then, it can be noted that the azeotropic composition occurs at $95.1 \% \mathrm{v}$.

Ethanol-water mixture can build stable bonding structure in all compositions. So every configuration described is in 


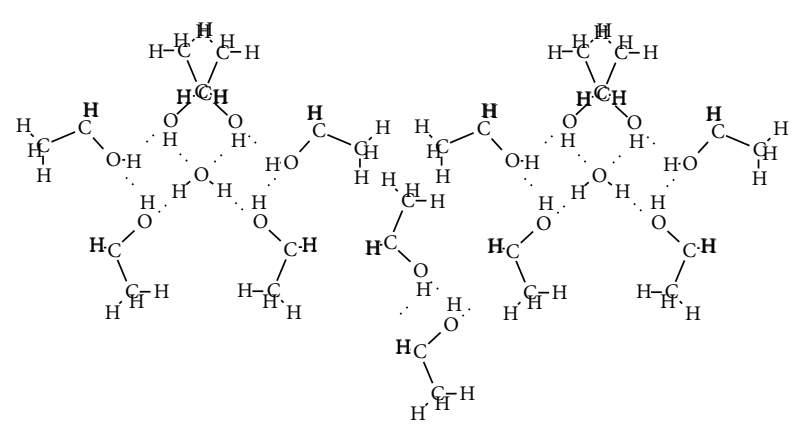

(a)

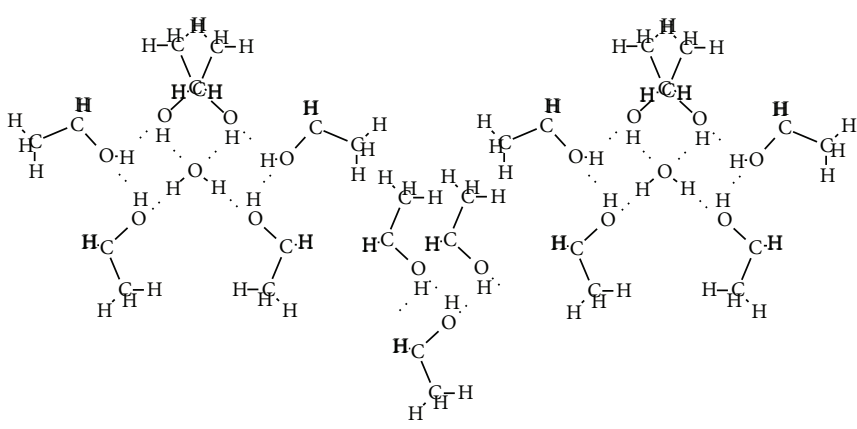

(b)

Figure 5: (a) Molecular structure of ethanol of $95.8 \% \mathrm{v}$. (b) Molecular structure of ethanol of $96 \% \mathrm{v}$.

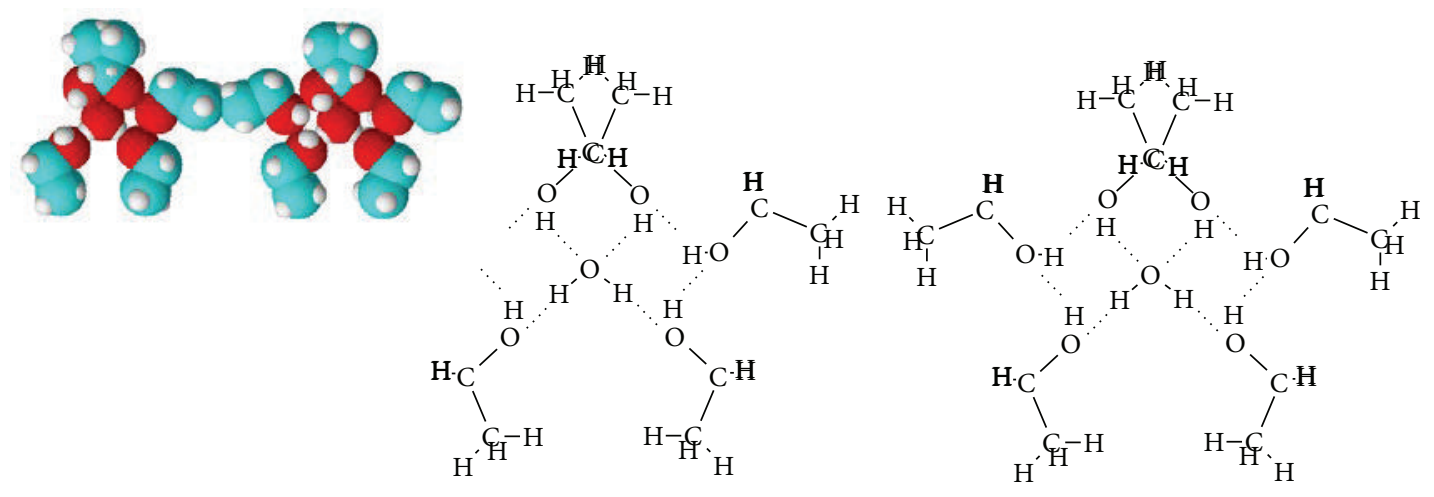

FIGURE 6: Molecular structure of ethanol of $94.7 \% \mathrm{v}$.

the minimum energy state at liquid phase. However, at vapor condition, only azeotropic ethanol molecule is stable with minimum energy state because its boiling point is lower than pure ethanol $[4,6]$. This is confirmed by the fact that, at the distillation process, azeotropic nature still exists. In azeotropic composition, the water molecule is a center of the cluster that serves as oxygenated compound resulting in better combustion characteristics. The additional ethanol molecules exist as free molecules from azeotropic molecular cluster.

By increasing the number of ethanol molecules, the heat value of fuel increases [6]. However, the ethanol molecules tend to bind each other so that the chain becomes longer. When two groups of azeotropic ethanol molecules are added to one molecule of ethanol, the composition becomes $95.5 \% \mathrm{v}$. This composition has a higher calorific value than azeotropic ethanol. In this case, cluster of hydrous ethanol consists of two groups of azeotropic ethanol molecules composed of twelve ethanol molecules and one free ethanol molecule. One ethanol molecule does not bind azeotropic groups, but it ties to other ethanol molecules. This one free ethanol molecule is equal to $7.7 \%$ of total molecules of ethanol. This composition is shown in Figure 4(b).

When the ethanol molecules are further increased, more ethanol molecules bind one another. This causes the bonds between the molecules to get even longer. So the heating value increases. Molecular configuration in Figure 5(a) is a cluster with $95.8 \% \mathrm{v}$ in which free ethanol molecules are $14.3 \%$.
Figure 5(b) shows ethanol which contains $96 \%$ v consisting of $20 \%$ free ethanol molecules.

On the contrary, when the water fraction is increased, heat value of fuel decreases. So there is a group capable of binding water resulting in chain length increases. Figure 6 shows the left group capable of binding another group. It is $94.7 \% \mathrm{v}$

4.2. Effect of Hydrogen Bond on Laminar Burning Velocity. When the mixture is ignited in the middle of the combustion chamber, the flame spreads to the radial direction from the igniter to the reactants. Figure 7 shows the growth of a fireball with increased diameter of $2.381 \mathrm{~ms}$.

Figure 8 shows $S_{n}$ of the spherical flame at various flame radius $r$ for lean, stoichiometric, and rich mixture at atmospheric temperature and pressure. The results show that $S_{n}$ in the rich mixture $(\phi=1.1)$ is higher than those at stoichiometric $(\phi=1)$ and lean $(\phi=0.9)$ mixture. This is consistent with the results of Liao et al. [20].

Figure 9 shows $S_{n}$ versus flame stretch rate $(\alpha)$, for hydrous ethanol of $95.5 \% \mathrm{v}$ at $\phi=1.1$ with 17 time repetitions. The value of $S_{n}$ at $\alpha=0$ is expressed as $S_{s}$ which is reasonably consistent. The average of those from 17 time repetitions increases confidence in $S_{s}$. On a small flame radius, the stretch is very high, so the flame speed is high. Furthermore, the speed of the flame slowly declines because stretch is reduced to achieve a situation in which the flame becomes unstable and is extinguished while touching the wall. 

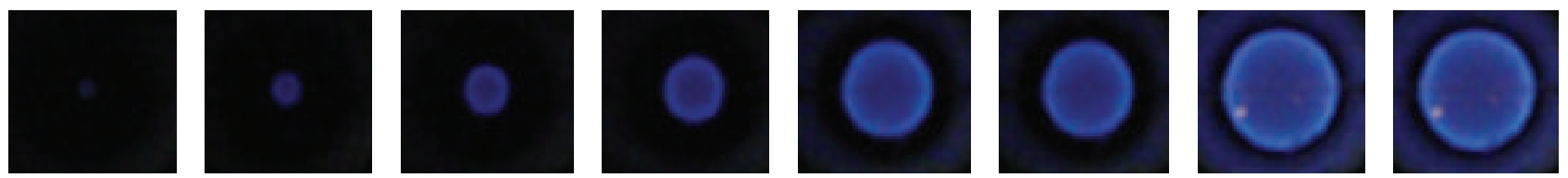

Figure 7: Typical growing image of flame radius for hydrous ethanol-air (95.5\%v). Time interval: $2.381 \mathrm{~ms}(\phi=1.1, T=305 \mathrm{~K}$, and $P=$ 1 atm).

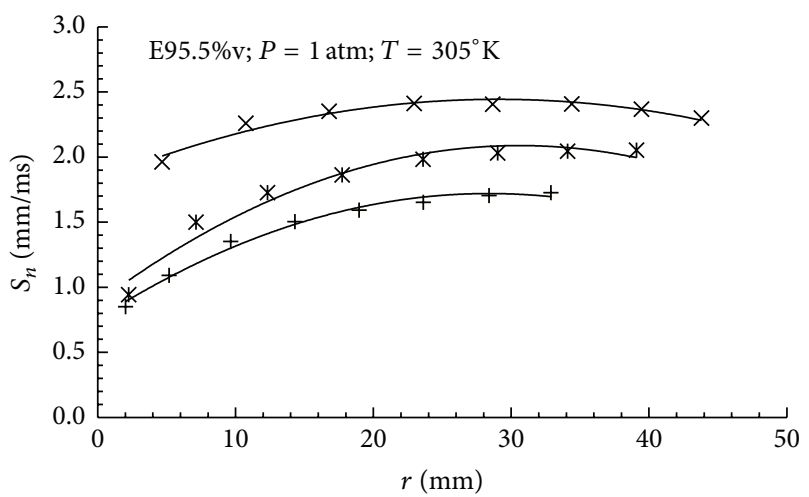

$\begin{aligned} \times \phi & =1.1 \\ * \phi & =1 \\ +\phi & =0.9\end{aligned}$

Figure 8: Flame speed versus the flame radius in lean, stoichiometric, and rich mixtures.

$S_{s}$ of hydrous and anhydrous ethanol at $\phi=1.1$ is estimated from $S_{n}$ at $\alpha=0$ as shown in Figure 10(a). Figure 10(b) shows $S_{s}$ of ethanol fuel based on the water content on each equivalence ratio. Flame speed decreases with the addition of water. At the composition around azeotropic level, $S_{s}$ increases dramatically with slight water addition. The maximum flame speed occurs in $4.5 \% \mathrm{v}$ water (or ethanol $95.5 \% \mathrm{v}$ ). With further increase in water, $S_{s}$ decreases drastically until the water reaches $5 \% \mathrm{v}$ (or ethanol $95 \% \mathrm{v}$ ). Furthermore, $S_{s}$ decreases proportionally to the water content in ethanol. This applies to the lean, stoichiometric, and rich mixture. It is also shown that the rich mixture of $95.5 \% \mathrm{v}$ ethanol has the same flame speed as anhydrous ethanol.

Figure 11 shows $S_{s}$ for anhydrous and hydrous ethanol at the lean, stoichiometric, and rich mixture. The results of the present study have a similar tendency to that of Bradley et al. [3]. The present results were slightly lower because Bradley et al. [3] used 100\% ethanol while this study used $99 \%$ ethanol. Besides, there is slight friction between the piston and the cylinder causing pressure to increase in the combustion chamber which is slightly lowering $S_{s}$.

Laminar burning velocity $S_{L}$ was obtained by multiplying $S_{s}$ in Figure 11 with $\rho_{b} / \rho_{u}$ as in (5). $S_{L}$ for the lean, stoichiometric, and rich mixture can be seen in Figure 12.

It appears in Figure 12(a) that water affects $S_{L}$, especially in lean mixture. The higher water content decreases $S_{L}$. However, $S_{L}$ at rich mixture of fuel containing a small amount of water is almost the same. This fact indicates that the nature of azeotropic ethanol has no effect on $S_{L}$ in this composition.

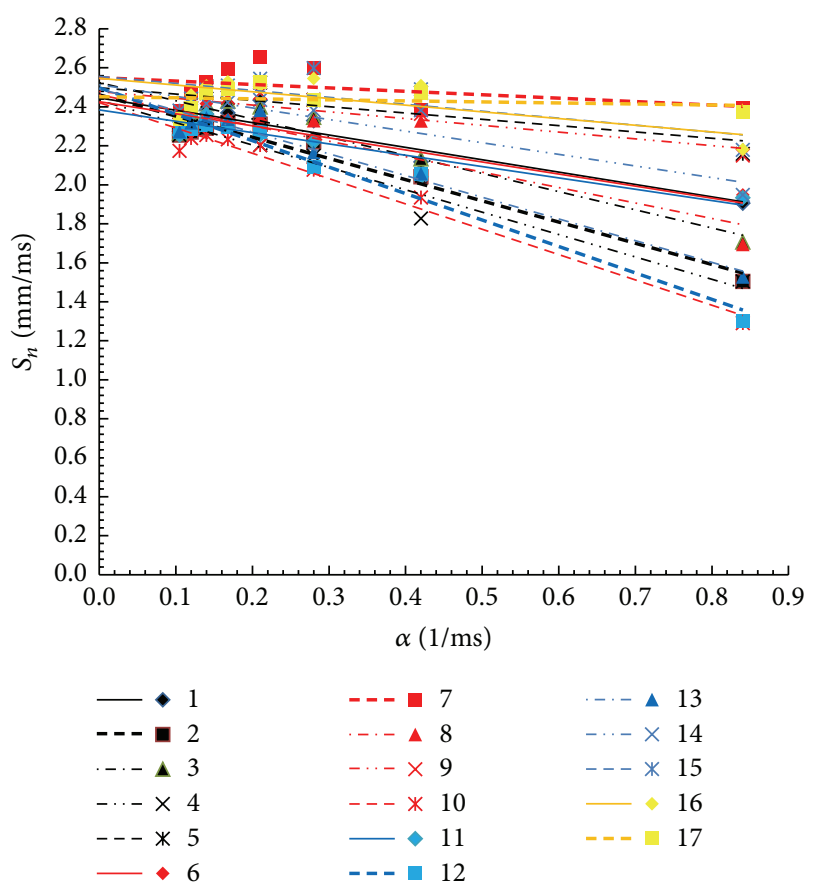

FIGURE 9: Flame speed of ethanol of $95.5 \% \mathrm{v}$ at $\phi=1.1, T=305 \mathrm{~K}$, and $P=1 \mathrm{~atm}$. Repetition performed 17 times.

It means that combustion characteristics of ethanol with composition higher than $96 \% \mathrm{v}$ are only influenced by the water.

Figure 12(b) shows that the water has no effect on $S_{L}$. It can be seen that $S_{L}$ of ethanol of $95.5 \% \mathrm{v}$ is higher than ethanol of $95.6 \% \mathrm{v}$ and $95.8 \% \mathrm{v}$ at all equivalence ratios. On ethanol of $95.1 \% \mathrm{v}$ to $95.8 \% \mathrm{v}$, azeotropic molecular properties overcome nonazeotropic molecular properties that affect $S_{L}$.

It is seen in Figure 12(c) that there are two groups of $S_{L}$. One group $(96,97,98$, and $99 \% \mathrm{v})$ represented by black lines is huddled in a rich mixture. And the other group (95.1, $95.3,95.4,95.5,95.6$, and $95.8 \% \mathrm{v})$ represented by red lines is not coincident. The $S_{L}$ group which is coincident with the rich mixture is mostly influenced by its water content. At this composition, the azeotropic ethanol is defeated by the nonazeotropic ethanol. The groups of $S_{L}$ which are not coincident are dominantly influenced by the nature of azeotropic group. Compared to anhydrous ethanol, azeotropic ethanol has a lower burning speed at lean mixture but has a higher combustion speed in a rich mixture.

All $S_{L}$ change following a similar trend with increasing equivalence ratio. At lean mixture, difference of $S_{L}$ is greater. 


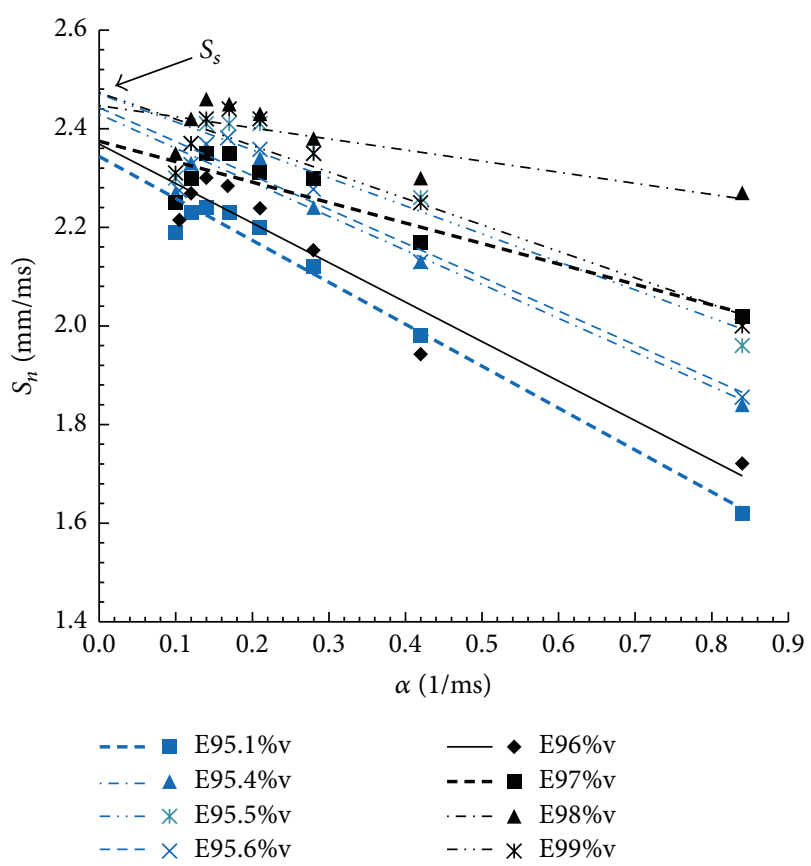

(a)

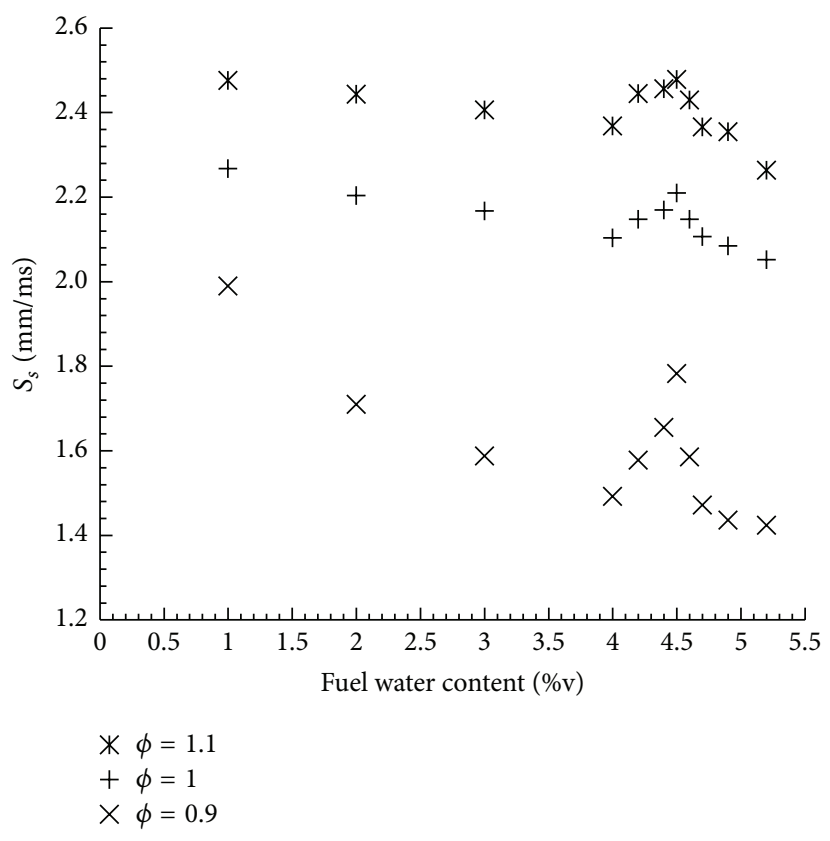

(b)

FIgURe 10: (a) Value of $S_{n}$ ethanol to flame stretched rate $\alpha$. (b) Value of $S_{s}$ ethanol to water content.

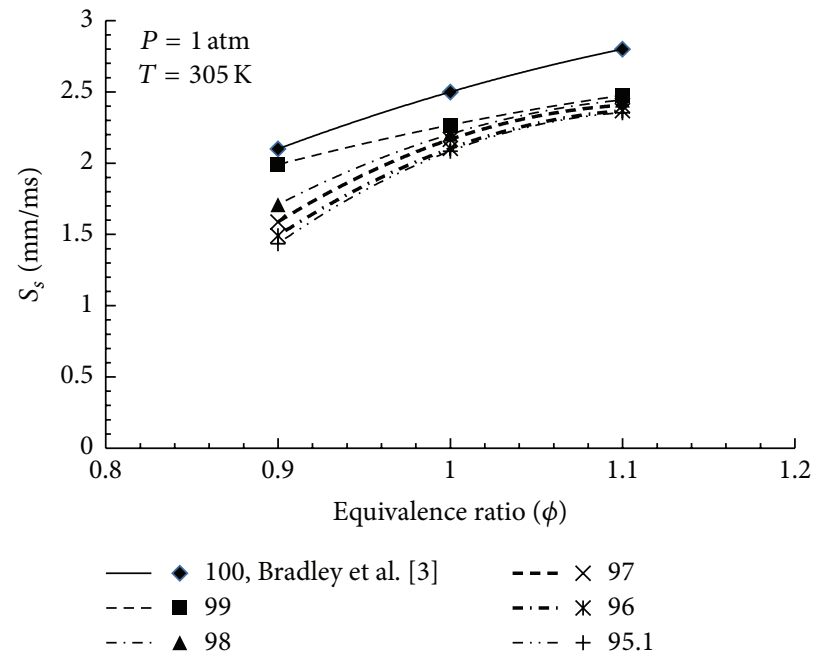

(a)

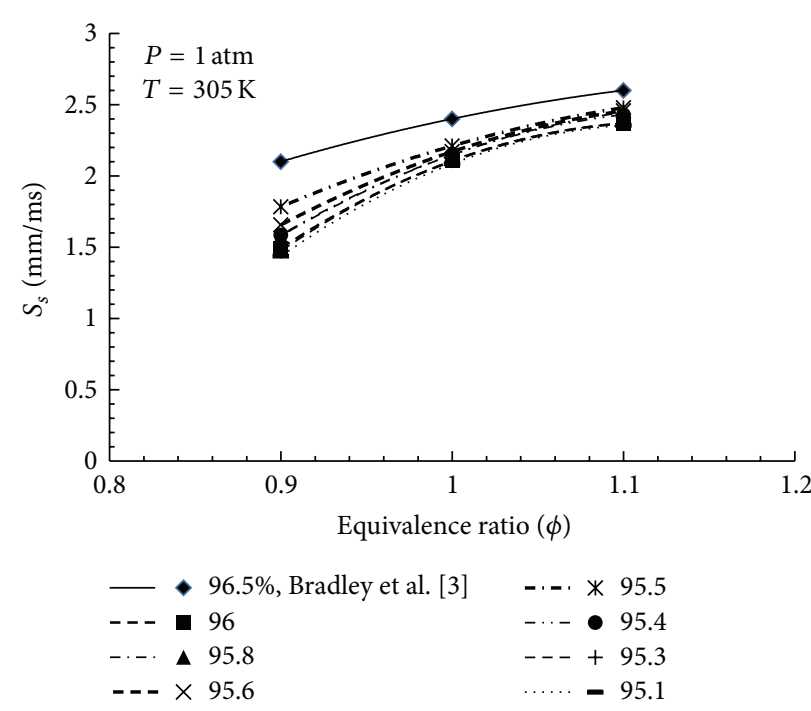

(b)

FIGURE 11: (a) Unstretched flame velocity of ethanol in various water content versus equivalence ratio. (b) Unstretched flame velocity of hydrous ethanol versus equivalence ratio.

This is due to fraction of air which is quite abundant in combustion process. Therefore, $S_{L}$ at the lean mixture is only influenced by the increase in heat value. Conversely, increasing the equivalence ratio to rich mixtures makes $S_{L}$ almost the same. In the rich mixture, hydrous ethanol contains little water which interacts to form a group. As a result, the water that serves as a centralized oxygenated compound helps the combustion process. In addition, the ethyl chain as a tail forms an angle to provide space for air to infiltrate into the interfuel molecules, so that it can enhance the combustion process. As a result, the burning velocity of ethanol of $95.5 \% \mathrm{v}$ is higher than that of $99 \% \mathrm{v}$. As a comparison, the distance between the carbon molecules in ethanol of $100 \% \mathrm{v}$ is very close so there is no air between the molecules of ethanol. In contrast, at ethanol $95.5 \% \mathrm{v}$, the ethanol molecules form a group which has a cavity that can provide space for the air to infiltrate to produce perfect combustion reaction. 


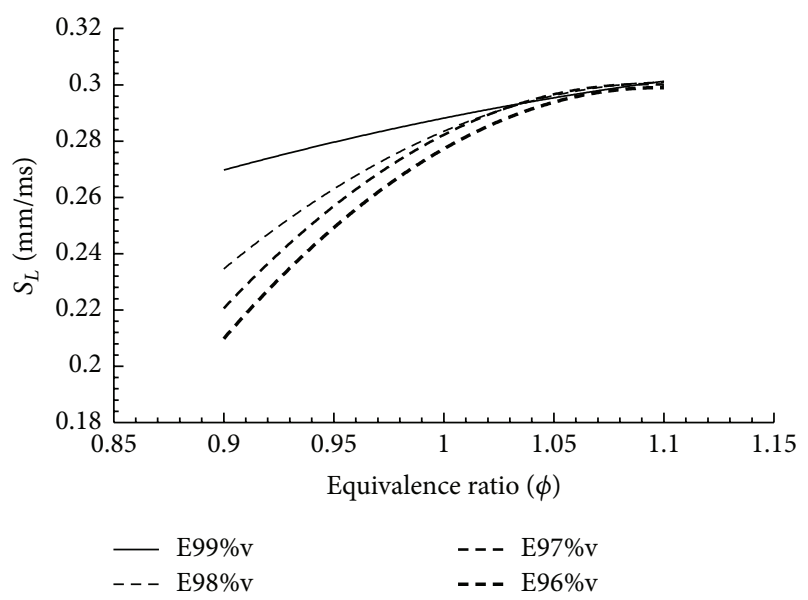

(a)

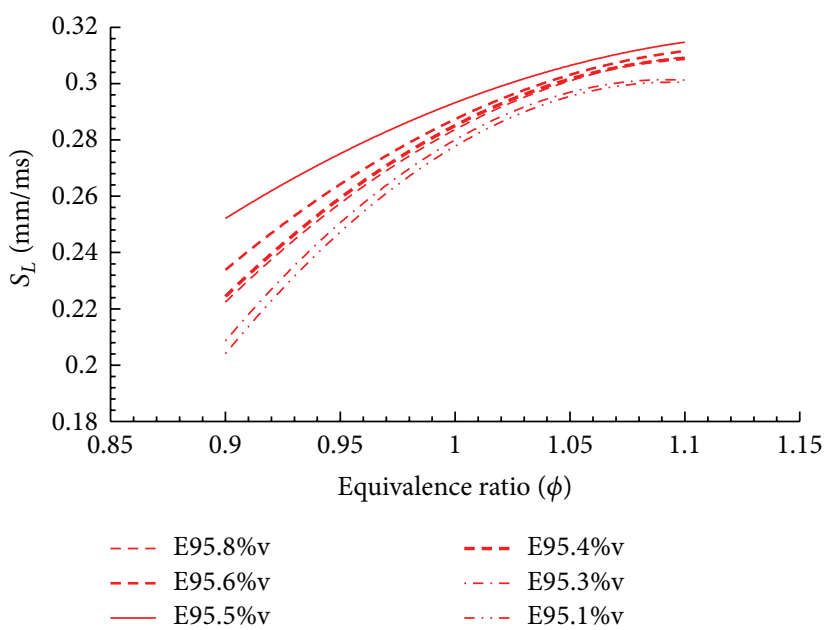

(b)

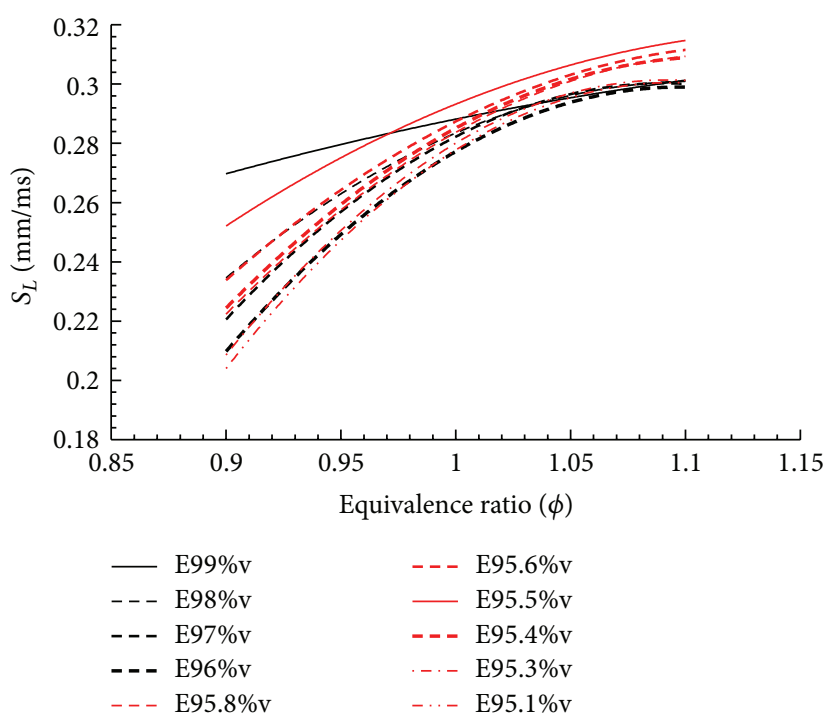

(c)

FIGURE 12: Laminar burning velocity of ethanol base of water content at lean, stoichiometric, and rich mixture.

$S_{L}$ is influenced by the physical properties and kinetic properties. Kinetic properties of fuel refer to chain length, heat value, and emissions generated. Combustion velocity increases as the ethanol fuel chain is short [21] and the calorific value is high. The calorific value of hydrous ethanol can be increased by adding free ethanol molecules to the cluster of azeotropic ethanol. However, the maximum burning velocity can only be obtained to a limited extent of free ethanol molecules. The results showed that the $95.5 \% \mathrm{v}$ ethanol which has $7.7 \%$ free ethanol molecules gives a maximum $S_{L}$. This result is also supported by [2] which suggests that the burning duration of hydrous ethanol of $95.6 \% \mathrm{v}$ is shorter than that of anhydrous ethanol.

When one free ethanol molecule is added to the two groups of azeotropic ethanol molecules, the result is ethanol of $95.5 \% \mathrm{v}$ and the percentage of free ethanol molecules is $7.7 \%$. This cluster is a form of short chain groups with centralized oxygenated compound, and $7.7 \%$ free ethanol molecule increases the calorific value. This molecule configuration gives the maximum laminar burning velocity at rich mixture.

Figure 5 shows that although the calorific value increases with further increase in free ethanol molecules, there are a growing number of ethanol molecules which bind each other to form long chains, which can reduce azeotropic characteristic which finally decreases $S_{L}$. Ethanol composition above $95.8 \% \mathrm{v}$ has more free ethanol molecules than the number of the azeotropic group, so its combustion characteristics are more affected by water content.

To summarize the role of molecule clustering by hydrogen bond in hydrous ethanol on laminar burning velocity, the distinctiveness parameters are tabulated as in Table 1 as a further detailed explanation of Figure 10(b).

\section{Conclusion}

The investigation on this study concludes the following: 
TABLE 1: The relationship between ethanol composition, number of water molecules, number of ethanol molecules, and laminar burning velocity.

\begin{tabular}{lcccccccc}
\hline $\begin{array}{l}\% \\
\text { EtOH }\end{array}$ & $\begin{array}{c}\text { Number of water } \\
\text { molecules }\end{array}$ & $\begin{array}{c}\text { Number of ethanol } \\
\text { molecules }\end{array}$ & $\begin{array}{c}\text { Number of ethanol } \\
\text { molecules free }\end{array}$ & $\begin{array}{c}\text { Number of molecules } \\
\text { involved in cluster }\end{array}$ & \multicolumn{2}{c}{$\begin{array}{c}S_{L}(\mathrm{~mm} / \mathrm{ms}) \\
\phi=0.9\end{array} \quad \begin{array}{c}\text { Molecules cluster } \\
\phi=1.1\end{array}$} & \begin{tabular}{c} 
configuration \\
\hline
\end{tabular} \\
\hline 95.1 & 2 & 12 & 0 & 14 & 0.204 & 0.278 & 0.300 & Figure 4(a) \\
95.5 & 2 & 13 & 1 & 14 & 0.252 & 0.293 & 0.315 & Figure 4(b) \\
95.8 & 2 & 14 & 2 & 14 & 0.222 & 0.284 & 0.309 & Figure 5(a) \\
96.0 & 2 & 15 & 3 & 14 & 0.210 & 0.277 & 0.299 & Figure 5(b) \\
\hline
\end{tabular}

(i) Based on the hydrogen bond molecule model, the azeotropic ethanol occurs at a $95.1 \% \mathrm{v}$ composition. At this composition, ethanol forms homogenous cluster which has the least amount of ethanol and water molecule in each cluster and short chain length that contributes to the lowest evaporation temperature.

(ii) Characteristic of laminar burning velocity of hydrous ethanol is influenced by the presence of free ethanol molecule around clustered molecules (azeotropic $95.1 \% \mathrm{v})$.

(iii) Maximum laminar burning velocity of hydrous ethanol occurs at a $95.5 \% \mathrm{v}$ composition. This case occurs in the presence of $7.7 \%$ free ethanol molecules of total molecules as heat addition.

(iv) Laminar burning velocity of hydrous ethanol $(95.5 \% \mathrm{v})$ at rich mixture is higher than anhydrous ethanol.

\section{Additional Points}

(i) Ethanol-water hydrogen bond molecule clustering was modeled.

(ii) Based on molecule model, it is concluded that the azeotropic behavior emerges from hydrogen bond clustering.

(iii) It is hypothesized that the laminar burning velocity reaches the highest level at azeotropic mixture.

(iv) The role of hydrogen bond molecule clustering in laminar burning velocity was observed experimentally.

(v) The discrepancy of the hypothesis with the experimental result was theoretically described.

\section{Competing Interests}

The authors declare that they have no competing interests.

\section{References}

[1] S. Saxena, S. Schneider, S. Aceves, and R. Dibble, "Wet ethanol in HCCI engines with exhaust heat recovery to improve the energy balance of ethanol fuels," Applied Energy, vol. 98, pp. 448-457, 2012.

[2] T. C. C. de Melo, G. B. Machado, C. R. P. Belchior et al., "Hydrous ethanol-gasoline blends-combustion and emission investigations on a Flex-Fuel engine," Fuel, vol. 97, pp. 796-804, 2012.

[3] D. Bradley, M. Lawes, S. Liao, and A. Saat, "Laminar mass burning and entrainment velocities and flame instabilities of ioctane, ethanol and hydrous ethanol/air aerosols," Combustion and Flame, vol. 161, no. 6, pp. 1620-1632, 2014.

[4] R. C. Costa and J. R. Sodré, "Hydrous ethanol vs. gasoline-ethanol blend: engine performance and emissions," Fuel, vol. 89, no. 2, pp. 287-293, 2010.

[5] I. Schifter, L. Diaz, J. P. Gómez, and U. Gonzalez, "Combustion characterization in a single cylinder engine with mid-level hydrated ethanol-gasoline blended fuels," Fuel, vol. 103, pp. 292298, 2013.

[6] B. B. Breaux and S. Acharya, "The effect of elevated water content on swirl-stabilized ethanol/air flames," Fuel, vol. 105, pp. 90-102, 2013.

[7] G. Li, Z. Zhang, F. You et al., "A novel strategy for hydrousethanol utilization: demonstration of a spark-ignition engine fueled with hydrogen-rich fuel from an onboard ethanol/steam reformer," International Journal of Hydrogen Energy, vol. 38, no. 14, pp. 5936-5948, 2013.

[8] B. M. Masum, H. H. Masjuki, M. A. Kalam, I. M. Rizwanul Fattah, S. M Palash, and M. J. Abedin, "Effect of ethanolgasoline blend on NOx emission in SI engine," Renewable and Sustainable Energy Reviews, vol. 24, pp. 209-222, 2013.

[9] A. Kyriakides, V. Dimas, E. Lymperopoulou, D. Karonis, and E. Lois, "Evaluation of gasoline-ethanol-water ternary mixtures used as a fuel for an Otto engine," Fuel, vol. 108, pp. 208-215, 2013.

[10] R. Munsin, Y. Laoonual, S. Jugjai, and Y. Imai, "An experimental study on performance and emissions of a small SI engine generator set fuelled by hydrous ethanol with high water contents up to 40\%," Fuel, vol. 106, pp. 586-592, 2013.

[11] J. M. Smith, H. C. Van Ness, and M. M. Abbott, Introduction to Chemical Engineering Thermodynamics, McGraw-Hill, New York, NY, USA, 2001.

[12] J. Beeckmann, L. Cai, and H. Pitsch, "Experimental investigation of the laminar burning velocities of methanol, ethanol, npropanol, and n-butanol at high pressure," Fuel, vol. 117, pp. 340350, 2014.

[13] Z. Zhang, G. Li, L. Ouyang, Z. Pan, F. You, and X. Gao, "Experimental determination of laminar burning velocities and Markstein lengths for 75\% hydrous-ethanol, hydrogen and air gaseous mixtures," International Journal of Hydrogen Energy, vol. 36, no. 20, pp. 13194-13206, 2011.

[14] R. J. Johnston and J. T. Farrell, "Laminar burning velocities and Markstein lengths of aromatics at elevated temperature and pressure," Proceedings of the Combustion Institute, vol. 30, no. 1, pp. 217-224, 2005. 
[15] X. J. Gu, M. Z. Haq, M. Lawes, and R. Woolley, "Laminar burning velocity and Markstein lengths of methane-air mixtures," Combustion and Flame, vol. 121, no. 1-2, pp. 41-58, 2000.

[16] X. Qin and Y. Ju, "Measurements of burning velocities of dimethyl ether and air premixed flames at elevated pressures," Proceedings of the Combustion Institute, vol. 30, no. 1, pp. 233240, 2005.

[17] http://www.acdlabs.com/.

[18] A. Nose and M. Hojo, "Hydrogen bonding of water-ethanol in alcoholic beverages," Journal of Bioscience and Bioengineering, vol. 102, no. 4, pp. 269-280, 2006.

[19] E. E. Fileti, P. Chaudhuri, and S. Canuto, "Relative strength of hydrogen bond interaction in alcohol-water complexes," Chemical Physics Letters, vol. 400, no. 4-6, pp. 494-499, 2004.

[20] S. Y. Liao, D. M. Jiang, Z. H. Huang, K. Zeng, and Q. Cheng, "Determination of the laminar burning velocities for mixtures of ethanol and air at elevated temperatures," Applied Thermal Engineering, vol. 27, no. 2-3, pp. 374-380, 2007.

[21] E. Ranzi, A. Frassoldati, R. Grana et al., "Hierarchical and comparative kinetic modeling of laminar flame speeds of hydrocarbon and oxygenated fuels," Progress in Energy and Combustion Science, vol. 38, no. 4, pp. 468-501, 2012. 


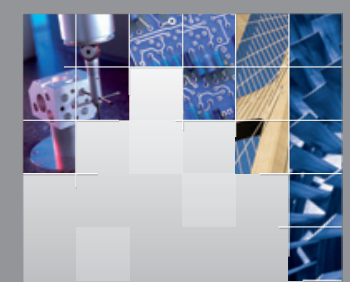

\section{Enfincering}
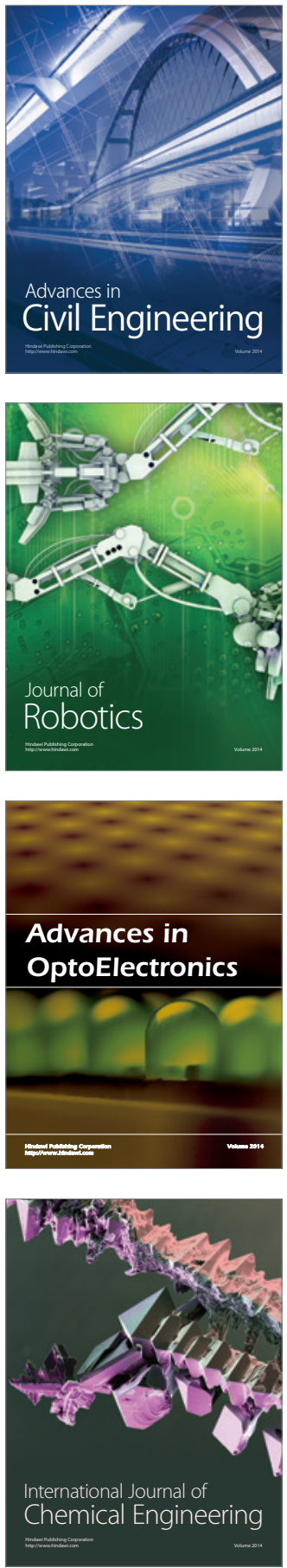

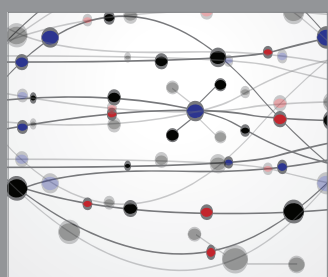

The Scientific World Journal

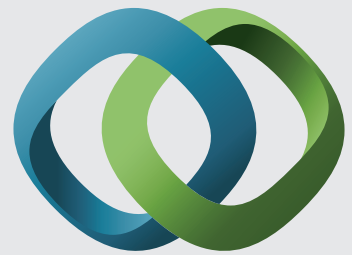

\section{Hindawi}

Submit your manuscripts at

http://www.hindawi.com
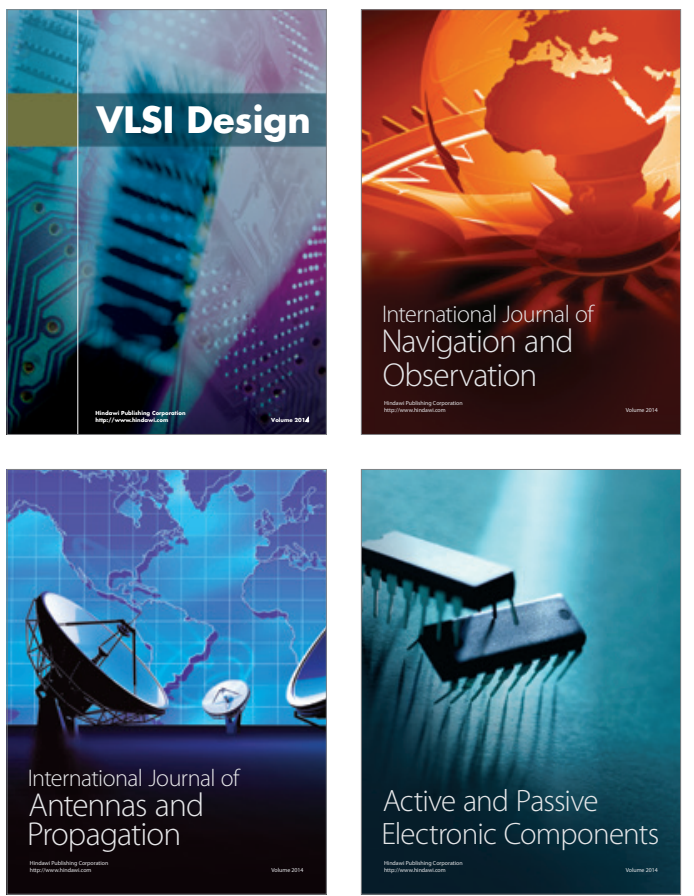
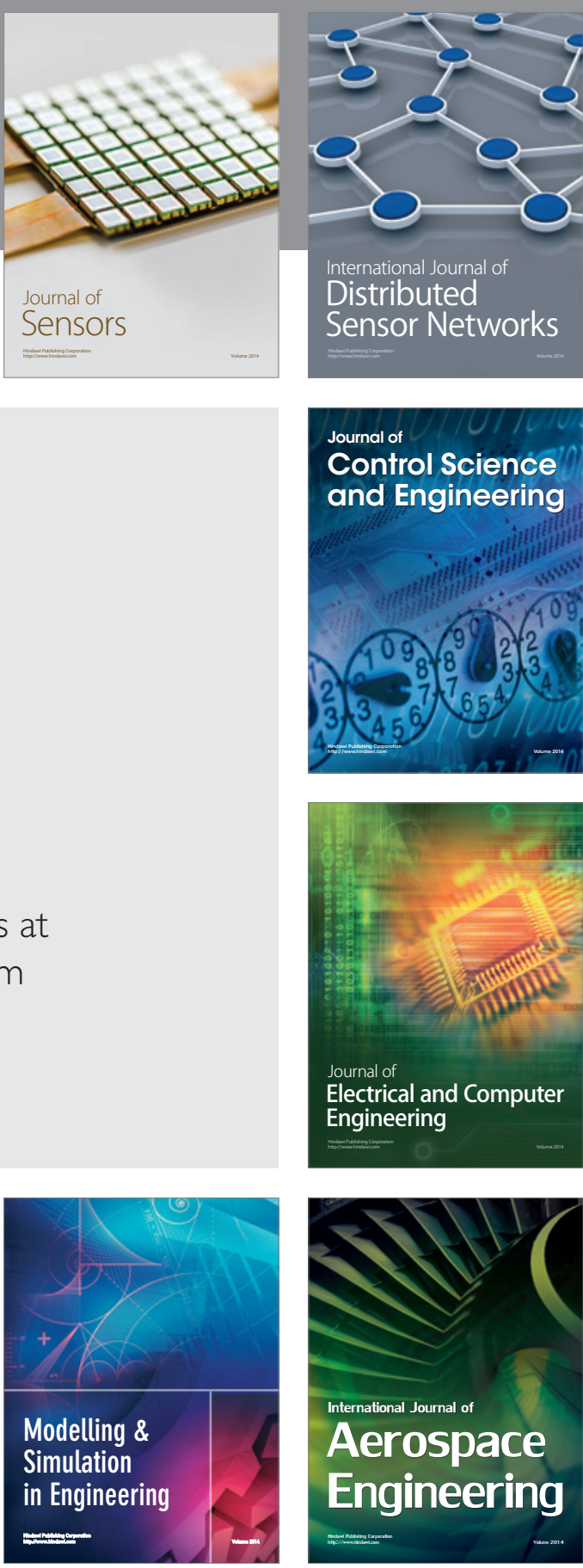

International Journal of

Distributed

Sensor Networks

Journal of

Control Science

and Engineering
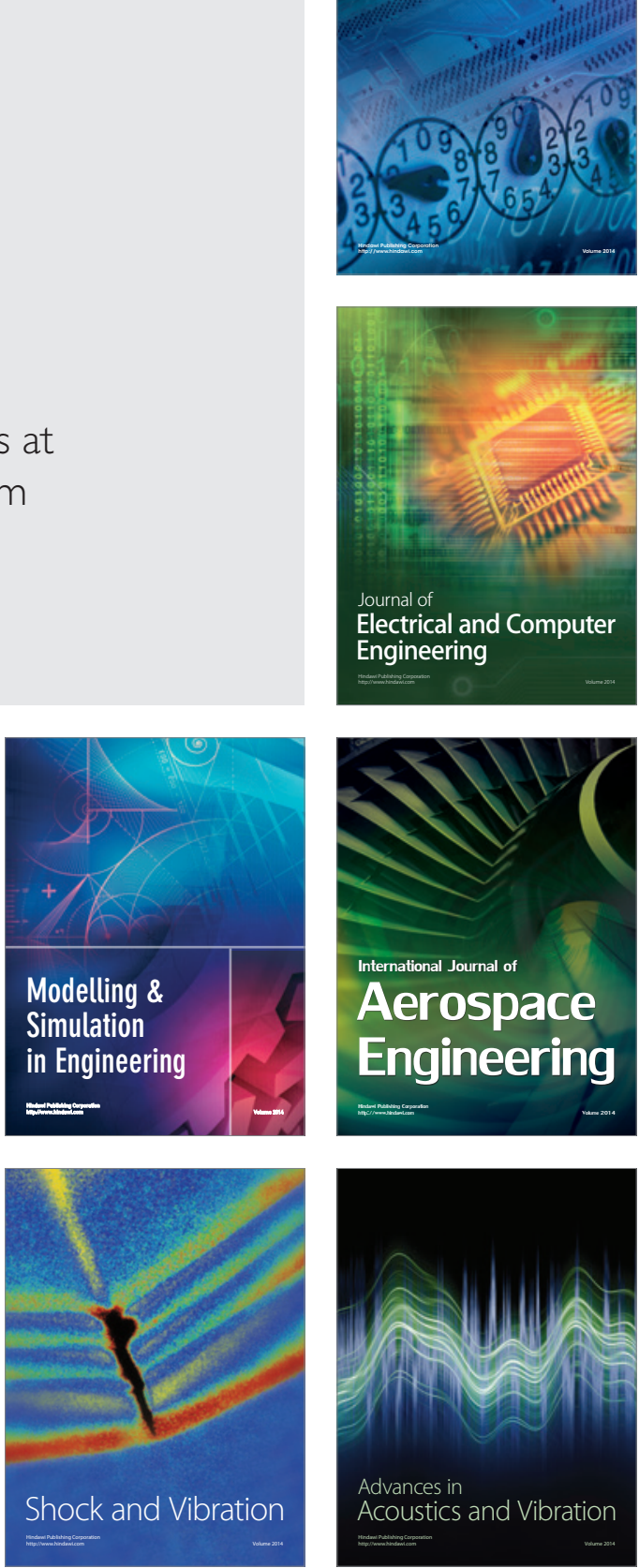